\title{
El pasado en el presente: explorando historias indígenas en Bolivia
}

\author{
Andrew CANESSA \\ University of Essex \\ canessa@essex.ac.uk
}

Recibido: 21 de enero de 2013

Aceptado: 15 de marzo de 2013

\section{RESUMEN}

Este artículo analiza el modo en el la gente de una aldea aymara-parlante entiende la historia y el lugar que ocupa en ella, examinando las profundas diferencias entre la conciencia histórica y la «corriente principal» de la indigeneidad. Plantea preguntas acerca de cómo las personas se relacionan con su pasado, la importancia de la conquista para los pueblos indígenas y las consecuencias para la política indigenista contemporánea de la existencia de una conciencia histórica indígena radicalmente diferente a lo que se supone comparten todos los indígenas.

Palabras clave: Indigeneidad, historia oral, identidad, Bolivia, aymara.

\section{The Past in the Present: Exploring Indigenous Histories in Bolivia}

\begin{abstract}
In this article I analyse the ways in which the inhabitants of an Aymara-speaking village understand history and their place within it and explores the profound differences between their historical consciousness and that of mainstream indigenous expression. This raises questions about how people relate to the past, the importance of the Conquest for indigenous peoples, and the consecuences for contemporary indigenous movements of the existence of an indigenous historical consciousness radically different to what is supposed all indigenous people share.
\end{abstract}

Key words: Indigeneity, oral history, identity, Bolivia, Aymara.

Sumario: 1. Introducción. 2. Ser indígena o no en Wila Kjarka. 3. Wila Kjarka y el pasado. 4. Conclusiones. 5. Referencias bibliográficas.

\section{Introducción}

En la actualidad es muy corriente hablar de la globalización de la indigeneidad (Niezen 2003; Tsing 2005) para referirse a cómo pueblos tan diversos como los sami noruegos y los dalits de la India se organizan bajo una bandera. Debido a tal diversidad y a la contingencia histórica, existe sin duda un debate sobre la adquisición analítica del término indígena (ver por ejemplo el iniciado por Adam Kuper (2003) en Current Anthropology); de igual forma, se ha derramado mucha tinta para definir la indigeneidad. En América Latina, al igual que en el resto del mundo, definir quién es y quién no es indígena y lo que significa esa identidad ha variado mucho, dependiendo del contexto y del momento específico; y cambia con el tiempo ${ }^{1}$.

Con anterioridad a la declaración del Decenio Internacional de los Pueblos Indígenas (1995-2004), Naciones Unidas encargó a Martínez Cobo un informe destinado a la Subcomisión para la Prevención de la Discriminación de las Minorías de Naciones

1 Ver por ejemplo Cadena (2000); Canessa (2005); Harris et al. (1995); Martínez Novo (2006). 
Unidas (1986), en el que definió a los pueblos indígenas de la siguiente manera: «las comunidades, pueblos y naciones indígenas son aquellas que, teniendo una continuidad histórica con las sociedades anteriores a la invasión y a la colonización que se desarrollaron en sus territorios, se consideran a sí mismas distintas a otros sectores de la sociedad que ahora prevalecen en dichos territorios o en parte de ellos $\rangle^{2}$. El informe de Martínez Cobo se ha convertido en un documento de referencia clave por su definición de la indigenidad, tanto para organismos internacionales y países (CEPAL 2005: 19; Saugestad 2001, 2004), como para antropólogos (Kenrick y Lewis 2004: 5). Un elemento clave en ésta y muchas otras definiciones es la idea de continuidad histórica con las sociedades pre-coloniales. Lo que no queda tan claro es de qué tipo de continuidad histórica estamos hablando, ni qué clase de historicidad se está invocando. Lo indígena es, sin duda, un concepto resbaladizo. Recientemente Marisol de la Cadena y Orin Starn han escrito que «un ajuste de cuentas con la indigeneidad exige reconocer que es un campo relacional de la gobernanza, subjetividades, y conocimientos que involucran a todos nosotros -indígenas y no indígenas- en la construcción y reconstrucción de sus estructuras de poder e imaginación» (2007: 3). $\mathrm{La}$ indigeneidad es claramente relacional, establece una distincion entre grupos y casi siempre se define en términos de características no compartidas con los grupos dominantes. A veces, las que actualmente se consideran formas culturales indígenas, pueden tener sus raíces en prácticas coloniales (Friedlander 1977), lo que apunta a la dinámica natural de la indigeneidad; esta se relaciona inevitablemente con poder e imaginación, como señalan Cadena y Starn (2007:24). Ser o no ser indígena es estar generalmente en una posición de relativa falta de poder, reclamando siempre justicia y el derecho a la misma, construyéndose todo ello sobre una base de relaciones históricas. La indigeneidad, por lo tanto, tiene que ver con la historia y con el poder.

En su forma más simple, la reivindicación de lo indígena se reduce a una demanda minima, relacional y estratégica: «nosotros estábamos aquí antes que vosotros» (Clifford 2007: 197). Mary Louise Pratt subraya esta idea al señalar que todas las «definiciones generales utilizadas para describir a los pueblos indígenas -indígenas, nativos, aborígenes, primeras naciones/originarios- se refieren etimológicamente a la prioridad en el tiempo y en el espacio. Esto, por supuesto, hace que el término sea relacional y retrospectivo» (2007: 398 ). No es posible tener una idea de la indigeneidad sin la existencia de una invasion u ocupación en algún momento de la historia. Simplemente no tiene sentido hablar de indígenas americanos antes de la llegada de los españoles, ya que hasta ese momento no había conciencia de compartir una posición o identidad común: en 1491 no había indios en las Américas; en 1492 había millones de ellos.

\footnotetext{
2 El texto completo dice: «Las comunidades, pueblos y naciones indígenas son aquellas que, teniendo una continuidad histórica con las sociedades anteriores a la conquista y pre-coloniales que se desarrollaron en sus territorios, se consideran a sí mismas distintas de otros sectores de la sociedad que en la actualidad prevalecen en esos territorios, o en parte de ellos. En la actualidad conforman sectores no dominantes de la sociedad y están determinados a preservar, desarrollar y transmitir a las futuras generaciones sus territorios ancestrales, y su identidad étnica, como la base de su existencia continua como pueblos, de acuerdo con sus propios patrones culturales, instituciones sociales y sistemas legales». Naciones Unidas Doc. E/CN.4/Sub.2/1986/7. Véase también Ad. 1-4.
} 
Existe una aparente arbitrariedad en la historicidad cuando esta depende de un acontecimiento determinado: en la Bolivia contemporánea son considerados indígenas aquellos a quienes se atribuye un origen anterior a la década de 1490; en cambio los que se piensa que son descendientes de españoles son excluídos de esa categoría. La indigeneidad no es simplemente una relación histórica basada en «nosotros estábamos aquí antes que vosotros», sino que es también la continuidad de unas relaciones específicas de poder persistentes en el tiempo. Como he argumentado en otro texto (Canessa 2007), la reivindicación de lo indígena es una demanda de justicia basada no simplemente en la prioridad temporal sino en un sentido de injusticia histórica.

Hoy los pueblos indígenas no se entienden como supervivientes culturales que se aferran a una pintoresca, particular y atávica cultura, sino más bien como herederos de una situación colonial que se ha mantenido a través del tiempo, pese a los cambios en las estructuras de poder y la opresión. Sugerir que un pueblo ha permanecido fosilizado durante siglos por carecer del suficiente dinamismo cultural o de una conciencia histórica determinada, se me antoja una ilusión, si no es una mera condescendencia. La continuidad significativa reside en la conciencia histórica antes que en específicas formas culturales.

En su importante contribución, Mary Louise Pratt (2007) expone las varias formas de esta historicidad, pero lo hace, al igual que otros autores, asumiendo el enfoque occidental de una historia lineal donde se suceden los acontencimientos y el pasado aparece como algo distante. Son muchos los líderes indígenas de todo tipo, así como organismos internacionales y documentos constitucionales, que reproducen ese modelo histórico planteado. Puede que sea fácil ver a los grupos indígenas como descendientes de los pueblos pre-coloniales, pero no está tan claro que dichos pueblos compartan esta idea de la identidad como ascendencia; hay muchas formas de entender ésta y la genealógica aparece sólo como una de ellas. Los pueblos o personas pueden creer que han heredado un modo de vida, una relación con los dioses, o una posición política en términos de injusticia histórica. Para ellos y sus comunidades esta forma de ascendencia puede ser mucho más significativa que el linaje. Centrarse en la ascendencia genealógica implica también una concepción de la identidad racial, es decir, biológica, la cual es probable que no sea compartida por mucha gente. Resultaría extraño que esta idea de la identidad como algo sanguíneo o genético -frecuente en la historia europea- sea compartida por otros pueblos fuera del Viejo Continente.

En la comunidad de Wila Kjarka, en Bolivia, donde he realizado trabajo de campo desde 1989, la gente no cree en la herencia consaguínea, y su relación con los pueblos anteriores no está basada en la ascendencia genealógica ${ }^{3}$. De esta manera no parece que entiendan su indigeneidad, si la entienden en absoluto, sobre la base de la relación entre colonizadores europeos y nativos indígenas.

El modelo genealógico de identidad es, como afirma Tim Ingold (2004), fundamentalmente colonial aunque, curiosamente, es adoptado por algunos activistas indígenas con posiciones anticoloniales. Resulta interesante que tanto activistas indígenas

\footnotetext{
3 Por el contrario, piensan que comparten un tipo particular de grasa corporal común a otros jaqi (personas indígenas) y que esa grasa se produce a través de una dieta específica, un modo de vida comunitario, así como a las relaciones establecidas con los antepasados (Véase Canessa 2012 capítulo IV).
} 
radicales como organizaciones internacionales (p. ej. la Organización Internacional del Trabajo) manejen una idea de la indigeneidad como un principio genealógico, específicamente de los pueblos precoloniales. Queda por ver, sin embargo, si todas las personas que podrían considerarse indígenas se conciben a sí mismas de esa manera, como expresan sus supuestos líderes.

El tema de la autoidentificación es sin embargo clave, existiendo una importante tensión entre ésta y el concepto de indigeneidad fundamentado en la descendencia histórica y en el linaje genealógico. Para disgusto de políticos indígenas extremistas, como el boliviano Felipe Quispe (entrevista con el autor) ${ }^{4}$, mucha población urbana, intelectuales e izquierdistas, han comenzado a identificarse como indígenas por razones exclusivamente políticas. La indigeneidad ha alcanzado una gran variedad de terrenos políticos tales como la antiglobalización, un tipo particular de nacionalismo ${ }^{5}$ y el hartazgo por la corrupción y la resistencia a las políticas anti cultivo de coca, por nombrar sólo algunas. En un país como Bolivia, donde la mayoría de la población puede reivindicar siempre descendencia indígena, tal vez no sea tan sorprendente que un gran número de personas se identifique como tal aunque también es cierto que hijos de padres europeos se hacen llamar indígenas en el contexto de una determinada expresión política. De hecho, varias de estas posiciones (en algunos aspectos contradictorias) se identifican con el patrimonio y la cultura indígena, así como con la elección de Evo Morales como presidente y es precisamente con la presencia de Evo Morales en el poder cuando la indigeneidad se ha convertido en parte de la ideología nacional. En el fondo lo que se encuentra es el debate de si el Estado puede decidir quién es y quién no es indígena, entendiendo la indigeneidad en términos de una relación con el mismo más que como un sistema de significados generado en el interior de una particular cultura.

El Estado, que es imaginado en términos históricos, se construye en América a partir de la independencia del poder colonial. La festividad más importante en Bolivia es el 6 de agosto, el Día de la Independencia; sin embargo muchos indígenas no lo celebran, ya que lo ven como una celebración de la gente blanca. Para la mayoría de los indígenas bolivianos, la independencia simplemente significa el traspaso del poder de una élite a otra, donde nada cambió, ya que en gran medida siguieron excluidos de los símbolos del Estado republicano. La excepción a esa situación fue la elección de Evo Morales como presidente en 2005. Al igual que él, muchos otros grupos nacionales han luchado desde siempre por ser incluidos, ser parte e incluso adueñarse de las celebraciones estatales ${ }^{6}$.

4 Felipe Quispe tiene una larga historia política pero adquirió su mayor importancia a principios de la década de 2000 cuando sitió la capital boliviana La Paz con éxito a través de un bloqueo de carreteras continuado. Su protagonismo se ha visto eclipsado sólo recientemente por Evo Morales como el más prominente y exitoso lider indígena.

5 El gobierno de Evo Morales es buen ejemplo de este nacionalismo que expresa la identidad nacional en terminos de lo indígena hasta en su carácter moral.

6 No obstante, el ejército boliviano consideró que no podía garantizar la seguridad del presidente indígena para asistir a la celebración oficial en la capital constitucional de Sucre en 2008, por lo que Morales no pudo participar, permaneciendo en la ciudad de La Paz donde la población indígena es mayor. Esta lucha es también evidente en las dificultades que el presidente tuvo con la Corte Suprema, el Senado y la Asamblea Constituyente, lo que impidió el control indígena de las instituciones estatales. 
En las características de varios movimientos indígenas, como el liderado por el presidente (y el Estado al que representa), se hace cada vez más evidente la existencia de un marco histórico concreto: fechas como 1492, 1826 (la independencia boliviana) y 1952 (la Revolución Nacional) se han convertido en momentos icónicos en torno a los conceptos de identidad y justicia. Los significados y consecuencias de esa historia son, por supuesto, ampliamente debatidos; no sucede así con el hecho de que sirvan como justificación del Estado y la nación.

Forrest Hylton y Sinclair Thomson (2007) ven la elección de Morales como una revolución consecuencia inevitable del curso de la historia, que fluye desde el periodo colonial hasta el presente. Los recuerdos de las revueltas de la década de 1790, así como de la Revolución Boliviana hace sesenta años, son elementos clave en una conciencia histórica que enfrenta a los pueblos indígenas con el Estado mestizo-criollo. Resulta tentador interpretar los recientes acontecimientos políticos en Bolivia, donde se aprecia el enfrentamiento entre pueblos indígenas y criollos, como la continuación de una baile ya conocido, baile en el que el atuendo cambia pero las coreografías, interpretadas al ritmo de la música, siguen siendo las mismas. Pero James Dunkerley (2007) advierte contra la seducción de esa visión simplista, desafiada por la politica étnica boliviana. La identidad étnica en el país nunca ha estado bien definida y los pueblos indígenas siempre han mantenido con el Estado mestizo-criollo una relación ambivalente, con momentos en los que lo han apoyado, pero también otros en los que han intentado socavarlo. Desde este punto de vista, más bien desordenado, del momento histórico, los danzantes son menos visibles, sus vestimentas aparecen húmedas, y cuando la luz fría de un amanecer andino llega, vemos a todo el mundo borracho en el suelo, donde brazos y piernas se entrelazan en un abrazo violento pero a la vez íntimo. No queda claro que alguna vez hubiera dos grupos bailando. Como en toda buena fiesta boliviana la banda sigue tocando, aunque no siempre en sintonía; y los participantes, con cara de sueño, tienen dificultades para saber quién es quién.

Con esta visión desordenada de la historia, la identidad indígena se hace mucho más difícil de precisar. Incluso en determinados momentos como el Octubre Rojo de 2003, la conciencia histórica es menos evidente de lo que se pudiera pensar. En esa fecha movilizaciones masivas derrocaron al presidente y el New York Times declaró que «los pueblos indígenas... arrebataron el poder a la elite blanca» en un artículo titulado «Donde los incas gobernaron, los indios aspiran al poder» (Where Incas Ruled, Indians are Hoping for Power, Forero 2004). En los años que precedieron a la caída del presidente Sánchez de Lozada, la gente se movilizó en contra de normas arbitrarias y políticas neoliberales que perjudicaron principalmente a los sectores más pobres de la población, pero no estaba claro en absoluto que estuviera motivada por una conciencia histórica indígena particularmente fuerte ${ }^{7}$. Se debe ser entonces muy cuidadoso para asignar una particular conciencia histórica a todos o a una mayoría de los pueblos indígenas, considerando las múltiples maneras en las que la gente entiende su historia y, por consiguiente, su identidad étnica.

7 Aunque es cierto que en esos días Evo Morales, como líder del sindicato cocalero, comenzó a descubrir el potencial de la retórica indígena. 


\section{Ser indígena o no en Wila Kjarka}

Wila Kjarka es un pueblo de habla aymara donde he realizado trabajo de campo continuadamente desde 1989. Se encuentra en el corazón de la política radical aymara, a medio día de camino de Achacachi, tiene poco más de 200 habitantes y no tuvo acceso por carretera hasta 2007. La población practica un modo de vida autosuficiente, complementado con salarios provenientes de la migración masculina temporal y algunos trabajos de artesanía.

Los wila kjarkeños escuchan las noticias en la radio de lengua propia y han sido testigos o participantes directos de las manifestaciones de los aymaras en la capital cantonal, Sorata, así como de su asedio en $2003^{8}$. Los wila kjarkeños tienen ciertamente una visión histórica, pero ésta no concuerda exactamente con la que ha sido común entre los líderes indígenas en las últimas décadas.

Aproximadamente entre 1880 y 1953 Wila Kjarka fue una hacienda. El derrocamiento del régimen hacendario constituye un hito importante en la historia oral de Wila Kjarka, marcando su sentido histórico y estableciendo una nueva relación con el Estado. Los wila kjarkeños tienen una larga historia de relaciones con el Estado, ya sea éste republicano, colonial, o inca. La población local de la cercana capital provincial, Sorata, considera a la gente de Wila Kjarka culturalmente diferente, visión que a veces se presenta en términos de descendencia pre o post colonial. Los wila kjarkeños recuerdan la discriminación y el racismo por parte de los residentes de Sorata, tanto en el pasado lejano como en el reciente, y mantienen una clara distinción entre ellos y los sorateños. En el censo de 2001, la comunidad aparece como casi $100 \%$ indígena; solo una persona, con seguridad el maestro de escuela, se presenta como no indígena (a pesar de ser un hablante nativo aymara).

Parece, sin embargo, que los habitantes de Wila Kjarka se encontraban entre la población boliviana a la que no se preguntó por su autoidentificación como indígena ya que, como sugiere el informe de la CEPAL (2005) sobre el censo boliviano de 2001, esa pregunta hubiera resultado redundante: visión a veces presentada en términos de descendencia pre o post colonial. No tuve la oportunidad de observar el proceso del censo en Wila Kjarka, pero pude investigar sobre cómo fue ese proceso y nadie declaró haber sido preguntado por si eran indígenas o por si eran miembros de una comunidad originaria.

Si se lo hubieran preguntado, muchos, posiblemente la gran mayoría, hubieran respondido que no, ya que en Wila Kjarka, «indígena» es un término que se aplica a los grupos de tierras bajas que habitan en la cuenca amazónica y para quienes dicho término es preferido por los activistas. A los ojos de los wila kjarkeños, esos pueblos se consideran decididamente inferiores en términos sociales y culturales, lo cual tiene obvias implicaciones cuando migran a las tierras bajas tropicales y entran en contacto o conflicto directo con ellos. Tampoco los wila kjarkeños se identifican como «aymaras»: ni siquiera es posible construir sintácticamente la frase «soy aymara» en el idioma; más bien se identifican como hablantes de aymara, lo cual no es lo mismo que

8 Cuando el ejercito boliviano entró forzadamente a Sorata para «rescatar» a los turistas y otros que fueron considerados víctimas de un asedio aymara. 
autoidentificarse como indígena. Por ejemplo a mí -a alguien que indudablemente es europeo- me colocaron en la categoría de los hablantes de aymara (aymarparliri).

Cuando hablan de sí mismos lo hacen, por lo general, como personas de Wila Kjarka (Wilakjarkankirinaka) o jaqi, una palabra que puede ser traducida como «gente», lo que excluye claramente a la mayoría de la población urbana, incluso a algunos locales que han emigrado recientemente a grandes pueblos y ciudades. Es decir, la gente de Wila Kjarka no reconoce compartir una identidad étnica con aquellos residentes urbanos que fueron registrados como indígenas en el censo de 2001, aun sabiendo que una considerable mayoría de los reconocidos como aymaras residen en zonas urbanas: el 59,3\% de la población. De hecho, los vecinos de El Alto, la ciudad satélite de La Paz con una amplia mayoría indígena, no son generalmente considerados por los wila kjarkeños como jaqi, incluso aunque hayan sido el origen de algunas de las políticas indígenas más radicales en los últimos años.

La palabra jaqi no puede traducirse del aymara como simplemente indígena. ¿Hasta qué punto, entonces, los habitantes de Wila Kjarka pueden ser considerados como indígenas si no se definen a sí mismos como tales? La solución, tal vez, la encontramos en la propia conciencia histórica. Yo argumento que lo indígena se entiende mejor como una relación social contemporánea articulada en términos del pasado. $\mathrm{Me}$ atrevería a afirmar que no se puede referir simplemente a un grupo marginal, culturalmente diferente, porque esto significaría que cualquier grupo en esas condiciones podría ser descrito como específicamente indígena. Coincido con Kuper (2003) en que la indigeneidad no funciona como un concepto antropológico mientras distinga arbitrariamente entre grupos, pero sí parece apropiado a la forma de identidad de un grupo específico, el cual se basa en la conciencia histórica y en un particular sentido de la (in)justicia a través del tiempo. Esto, sin embargo, no implica necesariamente una relación genealógica con el pasado, no existiendo ninguna razón para una interpretacion esencialista.

Existen numerosas maneras de discutir la identidad y diversas formas en las que la gente se distingue de quien considera el «otro». Los wila kjarkeños no tienen, en este caso, grupos de filiación y no consideran que compartir una sustancia como la sangre los haga jaqi, wila kjarkeños o, mucho menos, aymaras. De hecho, algunos miembros importantes de la comunidad como el shaman, Teodosio, son conocidos por tener ascendencia mixta y ello no ha afectado en absoluto a su posición o a su identidad, identificándolo como una persona culturalmente tradicional que puede comunicarse con los ancestros. Uno no es más o menos jaqi simplemente sobre la base de la genealogía, incluso de la relativamente reciente genealogía. Los wila kjarkeños, no obstante, reconocen a sus antepasados, aunque se les considera un colectivo de personas fallecidas que habita en las montañas y otros lugares geográficos claves. Uno se relaciona con estos ancestros no genealógicamente, sino por ser parte de una comunidad y participar en intercambios rituales con la montaña y otros antepasados (cf. Paulson 2006).

Los recién llegados pueden ser asimilados en la comunidad siempre y cuando se ajusten a los rituales comunitarios, y hay muchos ejemplos en el pasado de personas de fuera que se han integrado con éxito. La condición indispensable es poseer algún derecho sobre la tierra que pueda ser adquirido o heredado a través del matrimonio; la genealogía y la sangre, por lo tanto, no juegan ningún papel. 
No me quiero centrar en las muchas maneras en las que los wila kjarkeños se distinguen de los demás a través de las experiencias vitales, sino que quiero poner el énfasis en su sentido de la historia y en cómo se entienden a sí mismos en términos históricos. Si, como yo sostengo, la indigeneidad es fundamentalmente una relación social imaginada en términos temporales, entonces queda por ver qué conciencia histórica tiene la gente de Wila Kjarka. El elemento del que debemos partir es que, claramente, su sentido de la identidad no se construye a partir del momento de la llegada española hace 500 años.

Para los pueblos sin escritura, la historia se transmite a través de las narraciones del pasado, es decir, la historia y la tradición oral así como los mitos. Para Lévi-Strauss (1969:16), los mitos eran «instrumentos para la anulación del tiempo», funcionando tanto para dar cuenta de los orígenes de las personas como para hacer ese pasado mítico no sólo inteligible sino también accesible. Existen, por lo tanto, tantas formas de entender la historia como pueblos. Para muchas personas de Wila Kjarka la tradición oral y el mito remiten a un pasado que no se ha ido sino que simplemente permanece en otro lugar, es decir, reside en un espacio temporal que existe bajo la superficie de la tierra; el pasado es, por lo tanto, inmanente e íntimo.

En la Amazonía, la historia mítica da cuenta de, entre otras cosas, los europeos y su poder, así como de la tecnología que mostraron (Guss 1989; Gow 2001). En la actualidad es un lugar común afirmar que los mitos cambian con el tiempo. Así lo ha mostrado Peter Gow (2001) entre los piro, donde los agentes externos que han ido conociendo han sido incorporados a los mitos. Las historias que los wila kjarkeños cuentan tratan tanto de como hacer frente a la importante pregunta existencial de «quiénes somos», como a la de «quién son los de nuestro alrededor». En la medida en que la historia mítica trata de orígenes e identidades, articula lo que desde una perspectiva occidental puede considerarse como conciencia indígena. Es ésa conciencia histórica la que convierte en legítima, por ejemplo, la demanda de un territorio particular por parte de un pueblo. Si la indigeneidad ha de significar algo, tiene que implicar un sentido de conciencia histórica basado en la ocupación original (o al menos previa) de un territorio.

Los mitos cambian, pero no lo hacen necesariamente de forma uniforme en toda la comunidad. Es decir, esos relatos pueden necesitar cambiar para dar cuenta del sistema de creencias implantado por los misioneros españoles, pero se entiende que conservan un corpus común reconocible que podríamos denominar tradicional. La responsabilidad de la transmisión del mito, con o sin modificaciones, siempre suele estar delegada en unas personas particulares. Sin duda, en Wila Kjarka los mitos cambian, pero llama ponderosamente la atención las diferencias que apreciamos en las narraciones relativas al pasado más lejano. Las personas mayores relatan historias muy diferentes a las de la gente joven, aunque existen también importantes variaciones dentro de la misma generación. Incluso comunidades muy pequeñas pueden no compartir un mismo sentido de la historia y, por lo tanto, no poseer una identidad indígena compartida. Este estudio se diferencia notablemente de otras etnografías que muestran cómo un conocimiento común de la historia es fundamental para la identidad compartida por el grupo, así como para la capacidad de participar políticamente en la burocracia estatal, especialmente como pueblos indígenas (e.g. Rappaport 1998). 


\section{Wila Kjarka y el pasado}

\subsection{El amanecer}

En términos generales, los wila kjarkeños adultos dividen su historia en tres periodos: chullpa pacha, inka pacha y patruna pacha, encontrándose este marco histórico prácticamente en todo el ámbito andino. El primer periodo es el inicio de los tiempos, cuando vivieron los chullpas. Se habla de los chullpas en toda la región andina y, como también sucede en Wila Kjarka, se afirma que vivían en casas circulares con las ventanas mirando hacia el este. Cuando el sol salió se quemaron hasta chamuscarse? Cuando le pedí a Pedro Quispe, uno de los más antiguos residentes de la comunidad, que me contara quién vivió allá hace mucho tiempo, habló de chullpas, a quien describe como ancestros («los abuelos de los abuelos») que vieron el amanecer del mundo. Pedro describe el tiempo de los chullpas como aquel en el que la tierra era compartida habiendo suficiente para todos.

Los chullpas pertenecen claramente a un pasado muy lejano, aunque son también, de forma importante, parte del presente. Varios wila kjarkeños de mediana edad describen a determinados númenes como la Pachamama (la madre tierra) como si fueran chullpas. De estos, los que escaparon de los rayos del sol se escondieron bajo tierra. La Pachamama, que es la fuente de la productividad de la tierra, es agasajada con alcohol y el sacrificio de animales. Describir la Pachamama como chullpa es reconocer que el pasado no ha desaparecido, sino que está presente, aunque simplemente en un lugar diferente. Existe de igual forma una especie de relación de parentesco con la Pachamama. Los chullpas, la Pachamama, y otros espíritus que sostienen la vida son, en definitiva, los espíritus de los pasados difuntos de los wila kjarkeños. Es esta intimidad con el pasado y los espíritus de la tierra lo que constituye un elemento clave para entender cómo logran los wila kjarkeños definirse como seres humanos.

La diferencia entre las visiones de los ancianos y de las personas de mediana edad sobre los chullpas, es que los primeros eran capaces de dar muchos más detalles sobre los mismos, así como de la relación que éstos mantienen con otras entidades. No obstante, muchos adultos fueron capaces de mencionar las ofrendas realizadas a los chullpas en forma de pata de cerdo o chicha.

Los chullpas, considerados como la causa de muchas enfermedades de la piel, deben ser alimentados y ofrendados para evitar esos males en la medida de lo posible. Se les puede molestar como, por ejemplo, cuando se dinamita una nueva carretera. Según Teodosio, cuando abrieron un nuevo camino en Quruma, los chullpas se enojaron mucho y robaron las almas de algunos de los trabajadores; tuvieron que ser aplacados con mucho alcohol y algo de oro. Se les decribe como un tipo muy diferente de personas que vivían en la oscuridad (la noche es su día), que no conocían a Dios y eran grandes y peludos, pero que a pesar de todo seguían siendo personas. Doña Francisca asegura que eran «gente con pies y cabezas grandes». Los ancianos, en particular, hablan de ellos como personas, es decir, jaqi, la pala-

9 La palabra chullpa también se refiere a las tumbas anteriores a la conquista, a menudo altas torres con ventanas hacia el este donde se depositaban las momias de los muertos. 
bra que, como hemos visto, los wila kjarkeños usan para describirse a sí mismos y para distinguirse de los mestizos y criollos. Herculiano (de unos cuarenta años) se refiere a ellos como «gente de otro mundo; estos no eran queridos por Dios y no eran creyentes. Esa gente del pasado era del bajomundo, fueron llamados gentiles, los llamamos gentiles]», para luego añadir, «estos jaqi son también prójimos, en realidad no son diferentes» (Ukax mä jaqi masisaskarikiw janiw ukaxa wasa jaqikikapunirakiti).

En cierta medida los chullpas existieron y existen en una especie de mundo paralelo. En ése mundo de oscuridad los actuales animales salvajes eran los que tenían domesticados. Manuel, de unos sesenta años, me contó: «para ellos ya no hay más vida para ellos aquí. Si lo hubieran golpeado a Dios, ¿dónde estaríamos nosotros ahora? Quizá estaríamos sufriendo como ellos sufren. Sus animales se encuentran ahora en la naturaleza. El pájaro wikhu es su pollo. El zorrillo es su cerdo -lo ve, ellos tienen de todo-»). Un elemento clave en las discusiones sobre los chullpas es que, aunque fueron desterrados al mundo de abajo, no han desaparecido y siguen estando presentes hoy de alguna forma. Son del pasado pero a la vez existen en el presente, aunque sea en una dimensión espacial diferente.

Únicamente las mujeres de más edad mencionan cómo los animales personas podían hablar e, incluso, casarse entre sí. «Los sapos vestían pantalones y en ese tiempo la gente vivía con sapos y zorros también» (Doña Juana), «las mujeres jóvenes se iban con las serpientes y parían pequeñas serpientes». «Los zorros vestían corbata y seducían a las mujeres jóvenes, cuyos bebés ladraban cuando nacían». En el tiempo de los chullpas las relaciones entre seres humanos y animales así como las normas sociales eran claramente diferentes a las actuales. Podemos, de igual forma, encontrar ecos de esas prácticas en edades posteriores, cuando los hacendados o sus agentes seducían a las chicas indígenas (como el caso de la madre de Teodosio). El zorro se relaciona con el mundo no indígena de los criollos y quizá aquí Juana esté expresando un sentido histórico de la explotación de la mujer, incluso en la era pre-colonial.

Doña Francisca, al igual que otras mujeres, menciona los tesoros, vasijas de oro y plata, que tienen los chullpas y que de vez en cuando los habitantes de Wila Kjarka encuentra cuando están cavando la tierra. La cuestion del tesoro y la riqueza es importante cuando se habla de los incas que sucedieron a los chullpas en la superficie de la tierra. Hoy los indios son pobres, siendo ésta casi su característica más importante, según reflejan los wila kjarkeños en las conversaciones. En el pasado, sin embargo, los indios, es decir, jaqi, eran ricos. En esta idea yace la clave del sentido contemporáneo de justicia social: los indios son pobres y lo son, no por su condición de ser $j a q i$, sino porque su gran riqueza les fue en su día violentamente arrebatada. El sol que mató a los chullpas desterró a los supervivientes del bajo-mundo (utnakapana jiwaraskix pachpankaskiw sarakisa jaqhipa manqhan jakaspachay). El sol también dio paso a los incas, quienes lo incluyeron como uno de sus dioses. Para muchos wila kjarkeños el sol se equipara con el dios cristiano, siendo esta idea de suma importancia porque, según ellos, no fueron los españoles quienes trajeron la religión cristiana sino los incas. 


\subsection{Incas}

Los incas son recordados por dos motivos principales: su riqueza y su poder. También porque usaban el látigo, y éste es hoy un símbolo legítimo de autoridad ancestral. En el tiempo de los incas, ellos podían mover ríos y rocas tan solo usando sus látigos:

«Dicen que [los incas] podían cambiar el curso de los ríos, igualmente las piedras podían moverse por sí mismas después de recibir el azote del látigo del Inca. Moviendo las piedras podían cambiar el curso de los ríos, pero ahora no podemos hacer esas cosas. El Inca era muy fuerte. Dicen que ellos podían crear la piedra por sí mismos. Pero ahora no es así. Los españoles dispersaron a los incas; (chhukhutatawayxiwa). El tiempo de los incas está perdido; ahora estamos en otro tiempo. Este mundo ha cambiado y es otro (uka muntuxa wasa jaqukiptawayxi)».

Con estas palabras, Celestino Chino de unos cuarenta años, describe el poder de los incas y cómo su tiempo dio paso a otro. Relata con tristeza la partida de los incas, haciendo referencia a cómo unos mundos se convirtieron en otros y cómo unas épocas o periodos dieron paso a las siguientes. Muchos antropólogos (e.g. Harris 1995; Bouysse-Cassagne \& Harris 1987) han observado que en las poblaciones rurales andinas no se cuenta la duración de la historia como una serie de acontecimientos encadenados, sino por medio de diferentes mundos que sustituyen a otros anteriores. Entre estos acontecimientos no hay historia en el sentido occidental ni tampoco una medida del tiempo en años. Mis interlocutores nunca hablaban de la llegada española como un acontecimiento fechado ni de su presencia como algo datable. De igual forma, muchas personas, incluidas las de la generación de Celestino, no entienden el pasado en el sentido temporal en el que nosotros lo concebimos: algo irremediablemente pasado. En aymara, pasado se dice nayra, la misma palabra que para «ojos». Uno ve el pasado pero no puede «mirar hacia el futuro»; es el futuro el que es remoto y extraño mientras el pasado es familiar y conocido.

Los más ancianos hablan del pasado con notable familiaridad. Así es como Pedro recuerda a los incas:

«El rey inca era así, en la cima de la montaña. Entonces éramos niños, éramos como ese niño pequeño y era allí donde vivía el Inca, aunque no vimos cómo murió. Los incas pararon en la cima de aquella montaña... él era capaz de enviar piedras grandes por todas partes simplemente con el uso de su látigo... así es como él era... Pero en ese tiempo él no mató a los españoles, ellos debieron de dispararle... Pero cuando estaba a punto de morir, dijo 'no habrá más oro y plata', y con estas palabras mandó todo a la montaña con su látigo. Por eso el oro se encuentra en la montaña; por eso está allí abajo».

Pedro habla como si él mismo hubiera visto personalmente al Inca cuando era un niño, usando una expresión gramatical que denota la experiencia de primera mano (ukjaxa nanakaxa akhama chikusipxkpachataya, khayamakisipxkpachathwa jisk'itakisipxkpachathwa), lo que es de alguna forma inusual y asegura a Pedro una conexión inmediata con los incas. Habla también con pesar de la llegada de los españoles:

«Dios hizo que los españoles lucharan contra los judíos. Por ello estaban luchando, pero si no hubieran matado al rey inca entonces las cosas hubieran sido diferentes. Él nos hubiera dado mucho, hubiera estado vivo... como ha estado muerto no lo conocemos. (La riqueza) se perdió y no queda nada». 
La actual pobreza de los wila kjarkeños no se puede entender sin el conocimiento del asesinato del Inca a manos de los españoles y de como previamente se vio forzado a esconder la riqueza dentro de las montañas.

Para las personas mayores, como Teodosio, los incas no están perdidos o desaparecidos, sino que se encuentran en las montañas donde en ocasiones aparecen: se les pueden ver a la entrada de una cueva vestidos con sus mejores galas. Según Teodosio, le hablan directamente. Si uno tiene mucha suerte y es cuidadoso, puede hacer un buen negocio con el Inca y éste le dará oro, aunque es un trato peligroso ya que el Inca, en última instancia, tomará la vida de uno a cambio de esa riqueza.

«Los incas viven. Tú puedes ir, mirar y gritar y te responderán diciendo ‘¡hola!’. Hay una puerta y una casa sola que pueden verse desde abajo. Un día el Inca se me apareció en forma de mujer. La vi con un vestido y un sombrero marrón y un chal. Estaba lloviendo y en la cima de la montaña llamada Ququr ella estaba cantando: la la la... Antes de que pudiera preguntarle de dónde venía, ella se dio la vuelta y desapareció. Estaba muy cerca. 'Por qué fuiste allí solo', me dijeron cuando volví. 'Ese es un lugar encantado. Esa mujer inca debe de haber sido una yanqha (deidad femenina ctónica). Ella pudo haberte matado'».

Los wila kjrakeños pueden oir la voz de los incas como en otras partes de los Andes (Arnold 2006: 180), pero es más común escuchar hablar al Inca como el viento, especialmente en el ventoso mes de Agosto, cuando las deidades ctónicas están más presente.

El rey inca fue básicamente asesinado por los españoles pero, como los chullpas, no desapareció del todo y algunos wila kjarkeños dicen que los incas se escondieron en el interior de las rocas (ukapi awist'askam q'arqaruw puritayna). Es decir, a diferencia de los chullpas que se fueron bajo tierra, los incas simplemente fueron a un lugar diferente, dentro de las rocas o, como Pastor me dijo, a Paititi:

«En los antiguos días el inca Atahuallpa solía ir a Illampu en cuya cima había una vieja ciudad... Dicen que desde la capital del Imperio de Tiwanaku fueron con llamas a Illampu de camino hacia Paititi, que está en la selva cerca de Mapiri... Lo he visto desde lejos pero no he llegado allí porque no se puede. Dicen que hay una gran campana de oro en el centro de la plaza y cuatro grandes jarras de oro. Dicen que las jarras están siempre llenas, pero nadie puede llegar a este lugar porque está encantado y protegido por serpientes».

\subsection{Patrunapacha: los españoles y los hacendados}

Los wila kjarkeños distinguen entre personas jaqi y q'ara. Estas son otro tipo de personas, aquellas que viven en las ciudades y que no mantienen las relaciones «adecuadas» con los espíritus de la tierra y las montañas. Los incas son inequívocamente jaqi; «él era ciertamente jaqi, ese rey inca, él nos hubiera beneficiado» (jaqi kastatapaya uka inka riyixa, jaqi phawuratapaya). Es importante tener en cuenta que para muchas personas mayores el Inca era cristiano. Muchos creyeron que el cristianismo llegó con la primera aurora, la cual marcó el comienzo de una era bajo esta nueva religión. Herculiano, de unos cuarenta años, sin embargo, objeta: «en esos días solo veneraban al sol. No era su costumbre venerar al Dios Padre». Herculiano llama a este periodo 
de los españoles, el tiempo de los Yankis: «el tiempo de los Yankis es el momento en que Cristobal Colón entró y poseyó la tierra de Bolivia, Qullasuyu... Entonces, cuando los españoles vinieron, gente de otro país entró en la tierra de Bolivia. En esa época apareció la Biblia».

Como ya hemos mencionado, Pedro, como otros wila kjarkeños de su generación, no asocia la religión cristiana con la llegada de los españoles,

«Conocemos los cristianos desde el tiempo de nuestros ancestros. Ellos eran propietarios de esas tierras y ellos organizaron los campos en forma de sayañas. Distribuyeron la tierra y después nosotros tuvimos la tierra. Nosotros estamos continuando el camino que ellos dejaron, pero [los q'aras] no querían que nosotros aprendiéramos a leer. Después de la Reforma Agraria aprendimos a leer y ellos se fueron con sus leyes. La Reforma Agraria nos trajo nuevas leyes: el patrón decía que si los indios supieran escribir entonces nos podían contradecir, por eso nos quitaron nuestras tierras... En esos días el patrón no tenía miedo de latigarnos o de insultarnos. Nos llamaría «indio burrego». Tuvimos que arar los surcos sin un solo error. Cuando nos atrasabamos en el campo éramos golpeados con un látigo. Ahora trabajamos para nosotros mismos, los lugares que pertenecieron a la hacienda nos pertenecen ahora a nosotros. Comemos de esa tierra (nanakaya jichhaxa uraqi manq'asisipxkthxa)».

Aquí Pedro, como muchos otros, asocia el poder de los españoles con educación, más que con la existencia de una tecnología superior o una deidad poderosa. Esta cuestión está presente en todas las generaciones: el poder de la educación que puede ser usado para dominar a la gente y, como consecuencia, para liberarla. En palabras de Edmundo: «el español vino a abusar de nuestra gente; abusaron de nosotros y nos trataron como animales. Nuestros antepasados no hablaban o leían en español, y por eso trataron a nuestros ancestros como animales».

Este comentario ilustra por qué el idioma por sí mismo no es necesariamente relevante para definir lo indígena: particularmente porque ser un analfabeto monolingüe ha significado históricamente, incapacidad para defender la tierra propia. El objetivo de la escolarización de las primeras décadas del siglo XX era el aprender español para poder reclamar la tierra robada en los decenios anteriores. Hoy muchos padres (y profesores) se oponen a la educación bilingüe porque temen que el niño que aprenda una lengua indígena no tendrá las capacidades lingüísticas necesarias (es decir, el español) para defenderse y lograr así mayor progreso social y económico. En otras partes del mundo el hablar una lengua indígena es parte fundamental de la reivindicación étnica, pero no sucede así en Bolivia, donde las consecuencias políticas y simbólicas no están tan claras.

Lo que en los parametros historiográficos occidentales conocemos como el tiempo de los españoles y la época de las haciendas, aparece confuso y no bien definido en la comunidad. No se hace mención al Libertador Simón Bolívar o al Mariscal Santa Cruz, cuyas pinturas cuelgan en todas las aulas del país. No hay tampoco menciones a ninguna guerra en contra de los mandatarios coloniales.

Eugenio Ticona ofrece un relato típico:

«Los [españoles] mataron al rey inca Atawallpa. Ellos les ofrecieron oro 'te daremos oro'. Pero cuando los españoles aceptaron el oro, lo mataron de todas formas. Lo 
descuartizaron con cuatro caballos Atawallpa, Tupak Katari ${ }^{10}$. Desde entonces se quedaron a vivir en América. Pero nosotros sufrimos mucho. Por ejemplo: el pongueaje, cuando cada comunidad mandaba gente a trabajar para el patrón; tenían que llevar toda la comida y cocinarla para él, lechones y corderos. Si no hacían eso eran castigados. El capataz (mayordomo) nos hacía trabajar con su látigo; él nos latigaba arbitrariamente. Incluso los curas eran patrones... Y, si un jaqi no hacía lo que le decía el patrón éste simplemente le quitaba su tierra. Por otra parte, los patrones vendían los jaqis de una hacienda a otra. Compraban y vendían jaqis como si fueran animales».

Al preguntar a los wila kjarkeños cuándo se marcharon los españoles, la respuesta más común era «con la Reforma Agraria». La Reforma Agraria de 1953 tomó tierra de los patrones y se la dió a los campesinos, marcando el fin del régimen colonial. Las guerras coloniales del siglo XIX fueron totalmente irrelevantes para los habitantes de Wila Kjarka, ya que el gobierno de Bolivia pasó entonces de manos de los españoles nacidos en España, a manos de los españoles nacidos ya en el Nuevo Mundo. De hecho, el siglo XIX fue un periodo de apropiación de tierras indias y, probablemente, en la década 1880 es cuando Wila Kjarka dejó de ser una comunidad libre para convertirse en una hacienda en la que el patrón y su capataz tenían derechos feudales sobre los indios. A diferencia de muchas comunidades a orillas del lago Titicaca, cuyas tierras fueran expropiadas a finales del siglo XIX, los wila kjarkeños no recuerdan la fecha en la que su comunidad se convirtió en hacienda, ya que se asimila la derrota de los incas y la llegada de los hacendados. También guardan silencio sobre el derrocamiento del colonialismo y el nacimiento de la república.

Para los wila kjarkeños el gran momento anticolonial no es cuando los Andes dejaron de ser gobernados desde Madrid, sino cuando ellos tomaron el control sobre sus tierras. La tercera gran época de la historia termina, por lo tanto, en lo que podemos reconocer como la década de 1950. Se cuentan historias de cómo lucharon, mataron y quemaron la casa del hacendado con el fin de recuperar sus tierras ${ }^{11}$.

\subsection{La versión de la historia de los jóvenes}

Los wila kjarkeños mayores y aquellos en torno a los treinta años, comparten un marco histórico básico aunque con algunas diferencias. Todos ellos señalaron que todavía era posible relacionarse con los seres del pasado que se encuentran bajo tierra, tanto chullpas como incas. Los más jóvenes, en cambio, poseen una conciencia histórica diferente. La mayoría me aseguró que no sabía nada de los chullpas o los incas y que preguntara a sus abuelos. Cuando insistía, señalaban detalles muy básicos sobre ellos, como que el Inca movía piedras con su látigo. Pero no encontré a nadie de esa edad que produjera una secuencia histórica o expresara algún tipo de relación personal con

10 Atawallpa era el rey inca que fue capturado por los españoles en Cajamarca en 1532. Tupak Katari lideró una revuelta contra la norma española en los años de 1780 y fue, asimismo, descuartizado por caballos en 1783. Esta combinación de los dos podría entenderse como una confusión o como un reconocimiento de que la relación básica entre colonizador y colonizado no cambió esencialmente durante este periodo.

11 La historia se complica por una guerra por la tierra con una comunidad vecina que llevó a la destrucción de Wila Kjarka antes de que la revolución estallara. He desarrollado este tema de manera amplia en otro texto (Canessa 2012). 
el pasado. En general eran reacios a responder a todas mis preguntas; simplemente decían no saber.

Puede ser, por supuesto, que la gente joven en Wila Kjarka, al igual que quizá los jóvenes en otros lugares, simplemente no estén interesados en la historia, pero también sucede que esta generación de jóvenes ha pasado más tiempo escolarizada que sus padres, los cuales apenas lo estuvieron dos o tres años. El tiempo de escolarización parece alejarles de las actividades relacionadas con la tierra y los espíritus que la habitan (Arnold 2006). La viva relación con la tierra y las diferentes entidades se vuelve así irrelevante. Uno de los efectos más claros de la escolarización es que la emigración a las ciudades y el uso del español se convierten en elementos esenciales del «progreso», el cual implica un cambio de estatus étnico. Como parte de este proyecto pregunté a escolares jóvenes cuáles eran sus aspiraciones; sin excepción, todos ellos dijeron que querían dejar el pueblo y vivir en la ciudad o, en todo caso, en cualquier otra parte. Para estos jóvenes, es probable que no sean importantes las diferencias étnicas con los q'aras, en cambio, para la generación mayor que vivió bajo el látigo del hacendado, la historia proporciona una forma de entender la profunda diferencia entre indios y aquellos que les dominaron: blancos y mestizos. Esta historia, además, les proporcionó relación íntima con la tierra y sus habitantes del pasado, es decir, les dió un sentido claro de lo que podemos llamar indigeneidad, un sentido de justicia enraizado en la conciencia histórica aunque es evidente que ellos no usan esta palabra.

Los jóvenes, sin embargo, han crecido en un mundo donde el progreso social se ofrece (si no se entrega) y no tienen la experiencia personal de la violencia y la exclusión vivida por sus mayores. Lo significativo de estos testimonios del pasado es que, aunque hay claros elementos comunes, existe una considerable diversidad en esta pequeña población. No encontré evidencias de una narrativa continua que relacione procesos políticos e instituciones contemporáneas con los de la época incaica como encontramos en otros detallados trabajos etnohistóricos (Arnold 2006 y Abercrombie 1998). Ambos trabajos muestran que el desarrollo de un grupo indígena particular está relacionado con el de los estados incaico, colonial y republicano. En el argumento está implícito que la indigeneidad está enraizada en el continuo, aunque en evolución, proceso tanto de compromiso como de resistencia con el Estado, donde los modelos incaicos aparecen conscientemente asimilados a los contemporáneos. No está claro hasta qué punto estos ejemplos etnográficos se pueden generalizar y, lo que es más importante, entiendo que, por el contrario, existen importantes desacuerdos en el interior de las comunidades sobre el contenido y significado de la historia. Sugiero, por lo tanto, que la conciencia histórica no solamente varía considerablemente a lo largo de los Andes, sino que también puede hacerlo en el interior de las comunidades, tanto entre generaciones como entre géneros. Las mujeres, por ejemplo, tienen una relación diferente con el estado (post)colonial. Éste utiliza estructuras e imagenes para hacer lo indígena más femenino y, al mismo tiempo, convertir a las mujeres de las comunidades en «más indígenas» (Cadena 1995; Canessa 2005). 


\section{Conclusiones}

Es innegable que la indigeneidad es muy heterogénea en Bolivia y que hay muchas personas que poseen un profundo sentido del pasado y una relación íntima con sus ancestros, los antecesores de los incas, los chullpas. Este sentido del pasado en el presente se refleja en la importancia de entender cómo ser jaqi, en términos de una relación social compartida con los ancestros. Uno no puede ser simplemente jaqi. Ser jaqi, como se entiende en Wila Kjarka, implica vivir de una forma determinada y, sobre todo, comprometerse a través de los rituales y el trabajo con la vida de la comunidad, así como con el conjunto de los espíritus que habitan su territorio. La dinámica de la relación de las personas con el pasado es lo que apuntala sus relaciones sociales en el presente, otorgándoles un poderoso sentido de la justicia en el contexto de su exclusión económica y política. La conciencia histórica se manifiesta en las relaciones sociales del presente.

Los habitantes de Wila Kjarka comparte con otros grupos marginales (e.g. Ingold 2004; Kenrick y Lewis 2004) un sentido de la identidad que es dinámica y procesual, incluso enraizada en relaciones sociales contemporáneas, aunque invoquen una perspectiva histórica para dar sentido a lo que son. La descendencia lineal de los incas o de sus predecesores no parece interesar a nadie en Wila Kjarka. Es mucho más importante el sentido de parentesco con la gente que vivió antes que ellos y quienes, a sus ojos, compartieron un entendimiento de cómo relacionarse con las personas y los espíritus que habitan en el paisaje. Esta conciencia histórica de lo que son es claramente indígena aunque no sea ni genealógica ni esencialista. Está basada en la contemporaneidad más que en un apego romántico al pasado mítico, otorgándoles un poderoso sentido de la justicia en el contexto de su exclusión económica y política. El racismo, que solía ser estructural y mudo, es cada vez más notorio y público (Calla 2008) y en todos partes la gente se aferra a los símbolos históricos para afirmar su legitimidad. Claramente debemos resistir la tentación de simplificar y de asumir una conciencia histórica general. La pluralidad de historias, y quizá mucho más importante, de principios y marcos históricos, complica en gran manera nuestro entendimiento de la acción política. Los habitantes de Wila Kjarka pueden muy bien movilizarse en torno a una bandera indígena pero no se puede dar por hecho que la conciencia histórica y, por lo tanto, una identidad indígena específica que articulan los líderes, sea compartida por todos los demas.

Agradecimientos: Este artículo es una versión de un capítulo del libro Intimate Indigeneities: Race, Sex, and History in the Small Spaces of Life (Duke University Press 2012). Agradezco a Óscar Muñoz Morán su minuciosa corrección del texto.

\section{Referencias bibliográficas}

ABERCROMBIE, Thomas

1998 Pathways of Memory and Power: Ethnography and History among an Andean People. Madison: The University of Wisconsin Press. 
ARNOLD, Denise

2006 The Metamorphosis of Heads: Textual Struggles, Education, and Land in the Andes. Pittsburgh: University of Pennsylvania Press.

Bouysse-Cassagne, Thérèse y Olivia Harris

1987 «Pacha: En torno al pensamiento aymara», en Tres reflexiones sobre el pensamiento andino, de T. Bouysse-Cassagne, O. Harris, T. Platt y V. Cereceda, pp. 11-59. La Paz: HISBOL.

CADENA, Marisol de la

1995 «'Women are More Indian': Ethnicity and Gender in a Community in Cuzco», en Ethnicity, Migration, and Markets in the Andes, B. Larson y O. Harris, comp., pp. 329-348. Durham: Duke University Press.

2000 Indigenous Mestizos: The Politics of Race and Culture in Cuzco, Peru, 19191991. Durham: Duke University Press.

CADEna, Marisol de la y Orin Starn (comps.)

2007 Indigenous Experience Today. Londres: Berg.

Calla, Pamela

2008 «La radicalización de lo femino en el proceso constituyente boliviano». Trabajo presentado en la British Academy Link Programme Workshop 'Gender and Indigeneity in Bolivia and Mexico'. The University of Essex, mayo de 2008.

CANESSA, Andrew

2005 «The Indian Within, the Indian Without: Race and Sex in an Andean Hamlet», en Natives Making Nation: Gender, Indigeneity and the State in the Andes, A. Canessa ed., pp. 130-135. Tucson: University of Arizona Press.

2007 «Who is Indigenous? Self-identification, Indigeneity, and Claims to Justice in Contemporary Bolivia». Urban Anthropology 36 (3): 14-48.

2012 Intimate Indigeneities: Race, Sex and History in the Small Spaces of Andean Life. Durham: Duke University Press.

CEPAL [Comisión Económica para América Latina y el Caribe]

2005 Los pueblos indígenas de Bolivia: diagnóstico demográfico a partir del censo de 2001. Santiago de Chile: Naciones Unidas.

CLIFFORD, James

2007 «Varieties of Indigenous Experience: Diasporas, Homelands, Sovereignties», en Indigenous Experience Today, M. de la Cadena y O. Starn, comps., pp. 197-224. Oxford: Berg.

DUNKERLEY, James

2007 Bolivia: Revolution and the Power of History in the Present. Londres: Institute for the Study of the Americas.

Forero, Juan

2004 «Where the Incas ruled. Indians are Hoping for Power». The New York Times, 17 de julio.

FrIEDLANDER, Judith

2006 Being Indian in Hueyapan [1977]. Londres: Palgrave Macmillan.

Gow, Peter

2001 An Amazonian Myth and its History. Oxford: Oxford University Press. 
Guss, David

1989 To Weave and Sing: Art, Symbol, and Narrative in the South American Rainforest. Berkeley: University of California Press.

HARris, Olivia

1995 «Ethnic identity and market relations: Indians and Mestizos in the Andes», en Ethnicity and Markets in the Andes: Indian Economies and Commercial Adaptations $16^{\text {th }}-20^{\text {th }}$ Centuries, O. Harris, B. Larson y E. Tandeter, eds., pp. 351-390. Durham: Duke University Press.

HARRIS, Olivia y Broke LARSON (eds.)

1995 Ethnicity and Markets in the Andes: Indian Economies and Commercial Adaptations $16^{\text {th }}-20^{\text {th }}$ Centuries. Durham: Duke University Press.

HyLton, Forrest y Sinclair ThOMSON

2007 Revolutionary Horizons: Past and Present in Bolivian Politics. Londres: Verso.

INGOLD, Tim

2004 The Perception of the Environment. Londres: Routledge.

KENRICK, Justin y Jerome LewIS

2004 «Indigenous Peoples' Rights and the Politics of the Term 'Indigenous'». Anthropology Today 20 (2): 4-9.

KUPER, Adam

2003 «The Return of the Native». Current Anthroplogy 44 (3): 389-402.

LÉvi-STRAuss, Claude

1969 The Raw and the Cooked. Mythologiques, Vol. 1. Chicago: Chicago University Press.

Martínez CoBo, José

1986 The Study of the Problem of Discrimination against Indigenous Populations. United Nations Document E/CN.4/Sub.2/1986/7. Nueva York: Naciones Unidas.

Martínez Novo, Carmen

2006 Who Defines Indigenous: Identities, Development, Intellectuals and the State in Northern Mexico. New Brunswick: Rutgers University Press.

NIEZEN, Ronald

2003 The Origins of Indigenism: Human Rights Issues and the Politics of Identity. Berkeley: University of California Press.

Paulson, Susan

2006 «Body, Nation, Consubstantiation in Bolivian Ritual Meals». American Ethnologist 33 (4): 615-664.

PratT, Mary Louise

2007 «Indigeneity today», en Indigenous Experience Today, M. de la Cadena y O. Starn eds., pp. 397-404. Oxford: Berg.

RAPPAPORT, Joanne

1998 The Politics of Memory: Native Historical Interpretation in the Colombian Andes. Durham: Duke University Press.

SAUGESTAD, Sidsel

2001 The Inconvenient Indigenous: Remote Area Development in Botswana, Donor Assistance and the First People of the Kalahari. Uppsala: The Nordic Africa Institute. 
2004 «On the Return of the Native». Current Anthropology 45 (2): 263-264.

Tsing, Anna

2005 Friction: An Ethnography of Global Connection. Princeton: Princeton University Press. 